\title{
Development of dominant sequence characterized amplified region (SCAR) marker linked with plume moth (Exelastis atomosa Walsingham 1886) resistance in pigeon-pea
}

\author{
Ramya R. Mishra ${ }^{1}$, Atul Nag ${ }^{2}$, and Jogeswar Panigrahi ${ }^{1 *}$
}

\begin{abstract}
The mode of gene action governing resistance to plume moth (Exelastis atomosa Walsingham 1886) derived from pigeonpea (Cajanus scarabaeoides (L.) Thouars) accession ICPW-94 has been determined and the resistance alleles have been designated as $P P M_{1}$. The progenies of $\mathrm{F}_{2}$ population and $\mathrm{F}_{3}$ families derived from an interspecific cross $C$. cajan (L.) Huth ('ICP-26') $\times$ C. scarabaeoides (accession ICPW-94) revealed monogenic gene action for resistance to plume moth, and the dominant control by single locus or cluster of tightly linked alleles. Bulked segregant analysis (BSA) of $116 \mathrm{~F}_{2}$ progenies by using 143 parental polymorphic RAPD primers could identify a fragment OPA09 $9_{910}$ associated with plume moth resistance in coupling phase of linkage. Further single plant analysis of the $116 \mathrm{~F}_{2}$ mapping population revealed OPA09910 was linked to $P P M_{1}$ locus conferring host resistance to plume moth with recombination fraction (rf) value of 0.125 (12.7 cM of Kosambi function). The resistance specific fragment OPA09 910 was cloned, sequenced and converted into a sequence characterized amplified region (SCAR) marker, SCOPA09942, which was also closely associated (10.3 cM) with the locus $P P M_{1}$ with rf value 0.102. BLAST analysis with pigeon-pea genome sequence also confirmed its occurrence in CcLG02 (Scafseq.LG_V5.0fa) and contig 01597 (AFSP01.fsa1). This SCAR marker showed reasonable screening efficiency in the $\mathrm{F}_{2}, \mathrm{~F}_{3}$, and $\mathrm{BC}_{1} \mathrm{~F}_{1}$ lines, thus it can be used as genetic handle in marker-assisted introgression of the genomic fragment conferring plume moth resistance and screening of breeding lines in pigeon-pea.
\end{abstract}

Key words: BSA, Cajanus cajan, Cajanus scarabaeoides, interspecific population, linkage mapping, marker assisted breeding.

\section{INTRODUCTION}

Pigeon-pea (Cajanus cajan (L.) Huth) is a major grain legume crop of the world. This crop possessed a genome of 833.1 Mbp and distributed over 11 linkage groups (Singh et al., 2012; Varshney et al., 2012). The yield of this crop has constrained with various biotic and abiotic stresses. Among biotic stresses, a group of pests feeding on flowers, pods and seeds constitute the pod borer complex are of key concern in the pigeon-pea growing countries (Grover and Pental, 2003; Gnanesh et al., 2011). Pod borer complex comprises of Helicoverpa armigera (Hübner, 1805) (pod borer), Maruca testulalis (spotted pod borer), Lampides boeticus (Linnaeus, 1767) (blue butterfly), Exelastis atomosa Walsingham 1886 (plume moth) and Melanagromyza obtusa Malloch (pod fly), and incurred 30\%-80\% yield losses in pigeon-pea (Sharma et

\footnotetext{
${ }^{1}$ Sambalpur University, School of Life Sciences, Jyoti Vihar-768019, Sambalpur, Odisha, India.

${ }^{2}$ Sambalpur University, Institute of Information Technology, Jyoti Vihar-768019, Sambalpur, Odisha, India.

*Corresponding author (drjpanigrahi@gmail.com).

Received: 11 January 2015.

Accepted: 22 July 2015
}

doi:10.4067/S0718-58392015000500016 al., 2010). The pod borer complex was led by $H$. armigera as major pest by incurring $70 \%-80 \%$ of yield loss, and this loss was well supplemented by pod fly (70\%-80\%), blue butterfly (4\%-10\%) and plume moth (5\%-10\%) in pigeon-pea (Sharma et al., 2010). The host resistance to these pests is not available in the primary gene pool including cultivars and local land races of $C$. cajan. But, several genotypes of secondary gene pool belonging to C. scarabaeoides (L.) Thouars, C. acutifolius (F. Muell.) Maesen, $C$. sericeus (Benth. ex Baker) Maesen, and $C$. albicans (Wight \& Arn.) Maesen possessed with host resistance to pod borer $(H$. armigera $)$ and some of its allied pests including pod fly, blue butterfly and plume moth (Sujana et al., 2008; Panigrahi, 2011). Hence, the genetic control of resistance to these pests have been identified in pigeon-pea using interspecific populations involving accessions of $C$. cajan and $C$. scarabaeoides (Verulkar et al., 1997; Aruna et al., 2005; Mishra et al., 2013; Sahu et al., 2015). All earlier workers reported that, resistance to pod borer (caused by $H$. armigera) is controlled by dominant allele of a single gene. It has also been reported that low densities of glandular long and high density of non-glandular short trichomes were associated with the host resistance caused by $H$. armigera (Aruna et al., 2005). Similarly, resistance to M. obtusa (Pod fly) was 
governed by two recessive genes with complementary gene action (Verulkar et al., 1997). Further, Sharma et al. (2003) reported a negative association between pod wasp (Tanaostigmodes cajaninae) and pod borer. No report was available on inheritance of plume moth resistance.

The random amplified polymorphic DNA (RAPD) markers (Williams et al., 1990) coupled with bulked segregant analysis (BSA; Michelmore et al., 1991) has been used for molecular tagging and mapping of genes controlling agronomically important traits in various crops including pigeon-pea (Kotresh et al., 2006; Ganapathy et al., 2009; Dhanasekar et al., 2010; Mishra et al., 2013). Recent days, RAPD markers are not favored in breeding endeavors due to its inconsistency in amplification across the laboratories. Hence, the linked/ co-segregated RAPD markers were converted into SCAR marker based on sequence data prior to its introduction in crop breeding efforts. Literature evinced on development good many number of SCAR markers for effective application in mapping of genes agro-economic traits including biotic stress resistance in various crops, vis-a-vis their employment in marker assisted selection (MAS) programs (Gupta et al., 2006a; 2006b; Li et al., 2008; Dianese et al., 2010; Srivastava et al., 2012). However, there is no report available on development of SCAR marker and its application in pigeon-pea. In this communication the pattern of inheritance of genetic elements contributing plume moth resistance was explained using interspecific mapping population involving $C$. cajan (acc. ICP-26) and C. scarabaeoides (acc. ICPW-94), and development of a RAPD derived SCAR marker linked with plume moth resistance is reported.

\section{MATERIALS AND METHODS}

\section{Development of mapping population and screening for plume moth resistance}

The pods of individual parents and $116 \mathrm{~F}_{2}$ progenies derived from an interspecific cross of $C$. cajan (acc. ICP26) as female parent and C. scarabaeoides (acc. ICPW-94) as male parent were examined for the presence of exit holes on pod surface at every $7 \mathrm{~d}$. The evaluation entries for the $\mathrm{F}_{2}$ progenies were then scored on interaction phenotype (IP) scale of 1-9 (Mishra et al., 2013). Simultaneously, the laboratory based antibiosis assay using artificial diet (Armes et al., 1992) was performed to ascertain the survival and development of neonate larvae on fresh pods and lyophilized pod powder based diet (Mishra, 2013). On the basis of larval growth (larval weight) at the $10^{\text {th }}$ day the genotypes were assigned with IP score on 1-9 scale as $1=\leq 5.0 \mathrm{mg}$ increment in larval weight, $2=>$ $5.1 \mathrm{mg}$ and $\leq 10.0 \mathrm{mg}$ increment in larval weight, $3=>$ $10.1 \mathrm{mg}$ and $\leq 15.0 \mathrm{mg}$ increment in larval weight, $4=>$ $15.1 \mathrm{mg}$ and $\leq 20.0 \mathrm{mg}$ increment in larval weight, $5=>$ $20.1 \mathrm{mg}$ and $\leq 25.0 \mathrm{mg}$ increment in larval weight, $6=>$ $25.1 \mathrm{mg}$ and $\leq 30.0 \mathrm{mg}$ increment in larval weight, $7=>$
$30.1 \mathrm{mg}$ and $\leq 35.0 \mathrm{mg}$ increment in larval weight, $8=>$ $35.1 \mathrm{mg}$ and $\leq 40.0 \mathrm{mg}$ increment in larval weight, and 9 $=\geq 49.1 \mathrm{mg}$ and above increment in larval weight. Similar to this $12 \mathrm{BC}_{1} \mathrm{~F}_{1}$ plants and 50 progenies of $\mathrm{F}_{3}$ families were assessed for host resistance to plume moth in both field condition and laboratory based antibiosis assay, and all the progenies of $78 \mathrm{~F}_{3}$ families were assessed for its reaction to plume moth under field condition only.

\section{Isolation of genomic DNA and marker analysis}

Genomic DNA was isolated from young leaves of both the parents, $116 \mathrm{~F}_{2}$ progenies, $12 \mathrm{BC}_{1} \mathrm{~F}_{1}$ lines and $50 \mathrm{~F}_{3}$ progenies using modified CTAB protocol as described by Sivaramakrishnan et al. (1997), and were diluted to a final concentration of $20 \mathrm{ng} \mu \mathrm{L}^{-1}$ using $\mathrm{T}_{10} \mathrm{E}_{1}$ (10 mM Tris- $\mathrm{HCl}$ and $1 \mathrm{mM}$ EDTA) buffer for DNA marker analysis. The diluted genomic DNA of $20 \mathrm{~F}_{2}$ lines identified on the basis of field resistance $v i s-a$-vis antibiosis response were used to prepare two bulks, resistant bulk (RB; consisting of 10 plume moth resistant $\mathrm{F}_{2}$ plants with score 1 ) and susceptible bulk (SB; consisting of 10 plume moth susceptible $\mathrm{F}_{2}$ plants with score 8 and 9). A total of 143 synthesized decamer primers (Integrated DNA Technologies, Leuven, Belgium) showing parental polymorphism were used in bulked segregant analysis. The PCR amplification were carried out in a reaction volume of $25 \mu \mathrm{L}$ containing, 10X assay buffer, $1.5 \mathrm{mM} \mathrm{MgCl} 2,200 \mu \mathrm{M}$ of each dNTP, 0.3 $\mu \mathrm{M}$ primer, 1.0 units Taq DNA polymerase (Bangalore Genei Pvt. Ltd., Bengaluru, Karnataka, India). PCR amplification was carried out in a thermal cycler (Veriti-96; Applied Biosystems, Foster City, California, USA) under the following condition: initial denaturation at $94{ }^{\circ} \mathrm{C}$ for 5 min, followed by 45 cycles of denaturation at $94^{\circ} \mathrm{C}$ for 1 min, annealing at $37^{\circ} \mathrm{C}$ for $1 \mathrm{~min}$, extension at $72^{\circ} \mathrm{C}$ for 2 min and final extension at $72{ }^{\circ} \mathrm{C}$ for $5 \mathrm{~min}$. The amplified products were separated in $1.4 \%(\mathrm{w} / \mathrm{v})$ agarose gel and visualized on the gel documentation system (FireReader System, UVITEC, Cambridge, UK) and photographed.

\section{Bulked segregant analysis (BSA), development of SCAR marker and linkage analysis}

Of the 143 random primers, one primer OPA09 (5'-GGGTAACGCC-3') could amplify a specific band of about 910 bp in both resistant parent (C. scarabaeoides acc. ICPW-94) and resistant bulk which demonstrated its apparent association with plume moth resistance (Figure 1). The same reaction using primer OPA09 was performed in two other thermal cyclers (Mastercycler Pro, Eppendorf, Hamburg, Germany; My Cycler, Biorad, Hercules, California, USA) and reproducibility of the specific band verified. Further, the primer OPA09 was used for single plant analysis of $116 \mathrm{~F}_{2}$ progenies, and progenies having 'ICP-26' allele were scored as 'A' and those possessing 'ICPW-94' alleles were identified as ' $\mathrm{B}$ '. Recombination events between the locus conferring plume moth resistance and RAPD marker 


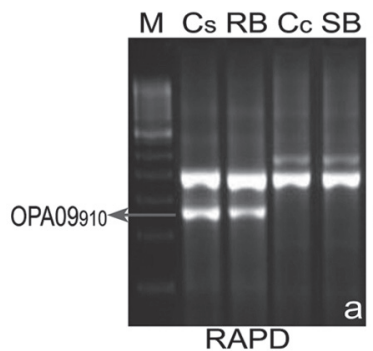

RAPD

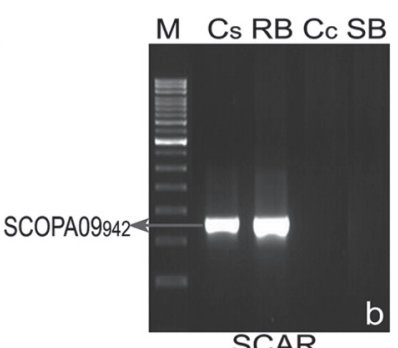

SCAR
Cs: Resistant parent (Cajanus scarabaeoides acc. ICPW-94); RB: resistant bulk; Cc: susceptible parent (Cajanus cajan acc. ICP-26); SB: susceptible bulk.

Figure 1. Bulked segregant analysis of plume moth resistance using RAPD primer OPA09 (a) and SCAR marker SCOPA09 S42 $_{2}$ specific primers (b); M: 250 bp step up ladder as molecular weight marker.

was computed and converted to map distance using Kosambi map function (Kosambi, 1943). Subsequently RAPD fragment was cloned using pTZ57R/T vector system using InsTAclone PCR cloning kit (Fermentas, Thermo Scientific, Waltham, Massachusetts, USA), and the plasmid DNA of recombinant clones were subjected amplification using S0100 and S0101 as forward and reverse primer as per the information available in cloning kit. The amplified fragment was sequenced in ABI-3500 Genetic Analyzer (Applied Biosystems, USA) and the fragment size was estimated to be $942 \mathrm{bp}$. Accordingly the SCAR marker is named as SCOPA09 ${ }_{942}$. Four pairs of forward and reverse primers were designed using web based software (Primer-BLAST, NCBI, Bethesda, Maryland, USA) using the border sequence cloned fragment, and one pair with primer sequences were: SCOPA09 ${ }_{942} \mathrm{~F}:$ 5'-GGGTAACGCCAAACCATAGA-3' and SCOPA09 942 R: 5'-GGTAACGCCGAAGCTCTCT-3' successfully amplified the target fragment. The components of the PCR reaction were the same as that described for RAPD analysis, except exclusion of $\mathrm{MgCl}_{2}$ and enhanced primer concentration $(10 \mu \mathrm{M})$. The optimized thermal cyclic condition was: initial denaturation at $94^{\circ} \mathrm{C}$ for $5 \mathrm{~min}$, followed by 30 cycles of denaturation at $94^{\circ} \mathrm{C}$ for $30 \mathrm{~s}$, annealing at $60^{\circ} \mathrm{C}$ for $30 \mathrm{~s}$, extension at $72{ }^{\circ} \mathrm{C}$ for $1 \mathrm{~min}$ and final extension at $72{ }^{\circ} \mathrm{C}$ for $2 \mathrm{~min}$. The SCAR primers succeeded in amplifying a single fragment in the resistant parent and resistant bulk identical to OPA09 $9_{910}$. The segregation of SCAR marker in $\mathrm{F}_{2}$ population was analyzed and its linkage relationship with the locus conferring plume moth resistance was estimated. The $942 \mathrm{bp}$ sequence was subjected to BLAST analysis using genome sequence of pigeon-pea (Varshney et al., 2012; Singh et al., 2012) to identify its position.

\section{RESULTS AND DISCUSSION}

\section{Inheritance of plume moth resistance}

The frequency distribution in the $116 \mathrm{~F}_{2}$ progenies, on the basis of their respective IP score gave good fit to 3:1 for plume moth resistance $\left(\chi^{2}=1.655\right.$ and $p$-value $\left.=0.198\right)$, indicating single dominant gene control for plume moth resistance. In $\mathrm{F}_{3}$ generation, the segregation pattern of 78 $F_{3}$ families for plume moth reaction was good fit for 1 (18 non segregating resistant): 2 (46 segregating): 1 (14 non segregating susceptible) ratio $\left(\chi^{2}=2.923, p\right.$-value $=$ 0.403 ), evidencing monogenic segregation pattern and single dominant gene action, as reported for pod borer resistance (Verulkar et al., 1997; Aruna et al., 2005; Mishra et al., 2013) and Fusarium wilt resistance (Kotresh et al., 2006) in pigeon-pea. This monogenic segregation for plume moth resistance was further established by $1: 1$ segregation pattern at $B C_{1} F_{1}\left(\chi^{2}=0.332, p\right.$-value $\left.=0.564\right)$ lines.

\section{Identification of RAPD marker linked to plume moth resistance}

Among the 143 RAPD primers distinguished the parental lines, one RAPD primer (OPA09) differentiated the resistant bulk from the susceptible bulk during BSA (Figure 1a) and generated a putative marker OPA0 $9_{910}$ associated with plume moth resistance in coupling phase. Single plant analysis of OPA09 $9_{910}$ among $116 \mathrm{~F}_{2}$ progenies revealed expected 3:1 segregation $\left(\chi^{2}=2.113\right.$ and $p$-value $=0.146$ ). Linkage analysis using segregation data showed $P P M_{1}$ locus was linked to OPA09 $9_{910}$ at 12.7 $\mathrm{cM}$ (recombination fraction 0.121). Only few reports pertaining to linkage association of RAPD markers with Fusarium wilt resistance (Kotresh et al., 2006), plant type (Dhanasekar et al., 2010), and pod borer resistance (Mishra et al., 2013) were available in pigeon-pea.

\section{Development of SCAR marker linked to plume moth resistance}

For precision and accuracy, the marker OPA0 $9_{910}$ was converted into SCAR marker named SCOPA09 ${ }_{942}$, and size of the amplified fragment is estimated to be $942 \mathrm{bp}$ with 41.3\% GC content (GenBank accession: KJ806291.1; Figure 2a). BLAST analysis with pigeon-pea genome sequence revealed its position on CcLG02, Scafseq.LG V5.0fa: 25623599-25622679 bp (Varshney et al., 2012) and contig 01597, AFSP01.fsa.1: 8557-7640 bp (Singh et al., 2012) with more than $99 \%$ homology for 2-922 bp sequence of the marker. This type of comparative genome analysis was first used for chromosome localization of blast resistance gene in rice (Sharma et al. 2005), and later on used for various traits related to biotic stress in several crops viz. aphid resistance in sorghum (Chang et al., 2012) and black rot resistance in Brassica oleracea (Saha et al. 2014). Out of four primer pairs designed on the basis of flanking sequence of cloned fragment, one primer pair (forward: SCOPA0 $9_{942} \mathrm{~F}$ and reverse: SCOPA09 ${ }_{942} \mathrm{R}$ ) amplified the expected fragment of 941 bp (Figure 1b) in both $C$. scarabaeoides (acc. ICPW-94) and the resistant bulk (Figure 1b). Thus, SCOPA09 ${ }_{942}$ behave as coupling phase specific dominant SCAR marker. Amplification pattern of SCOPA09942 among the $\mathrm{F}_{2}$ progenies is almost 
1 GGGTAACGCCAAACCATAGAGAATGCTTCTTATAACTGACCCGTGTGTAGTTTTATTTTA

61 CATTCCAGTTTTACCGTATCCACAATTATGTGGCCTATTGGCATTTGTTTAACAACTCCA

121 TCAAACGTACCAATCTTATATTGTTCTACAATCATGAAAAATAAAATAAAAAAATCAATA

181 TCTCTTTAGTTCGTTTTTGTTTTTTGGAGTTAACGAAATCGATAATTTTAATCAGAACAT

241 TCCATGCCTCTTTTACTTCGCCCGTACAAAACCAAAAAAAGAAGAAACGAAGACAGAAAT

301 AATAAATTGAGTCATAGTTATGTGGATTAAGTCCTTAACTTCAATCGACAATCCAGAATA

361 AATGCAATTCAAATAATTGAGACAAAACACAAAAAAACATCAATAAACGGTTCATTTCGG 421 GGATTGGGGACAGTATCCGAACAACTCGAATAGTATATGCGTAACGGCAACAGAAACCGA 481 GCATTGGCAAGTTTTCGGAACTAAATTTTCCTCATCGATCAAAACTCAAGCACGTTCGAC 541 TTGTCATTTTTTTTAACAGCATTCACAAATCGTAATTTCACAAGGCAACAACTGAGAACT 601 GTGGAATAGTAGCACTCACACAAAATGCTACCTGGTCCTTGCGGTCGTGTCCGTCGCCGG 661 AGATAGAGGCGGCGGCGGAACGTACGCCGGAGGAGGCGGTCTTAATGCAAGACGATATAA 721 ACTTGAAGGAAGAAGGAACAAATCCATTGCTCTTGCTGCAACCGTTGTCCTTGCTCTGAT 781 TCTTCATAATAATCAACGAAACTGTTTTCCACGGGCCACCGGTGAGTCACCGGGAATTCC 841 GTCGACGAGAGTCGCGGAACGCAGCCGATCGAATATAGCATAAGATTAAAAGGCGTCGGG 901 ATTCGCCGTACGCGGCGGCGGCAGAGAGCTTCGGCGTTACCC

$$
\text { SCOPA09942-R }
$$

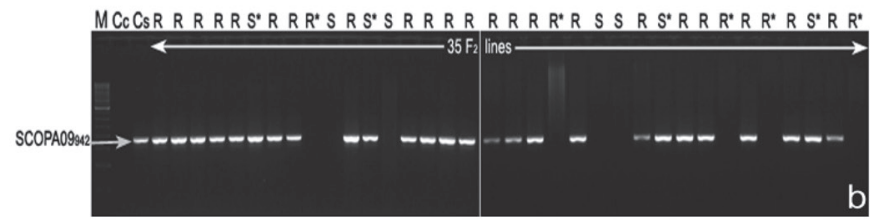

M: 250 bp Step up ladder, Cc: susceptible parent (Cajanus cajan acc. ICP-26), Cs: resistant parent (Cajanus scarabaeoides, acc. ICPW-94). *Reaction to plume moth (R: resistant and $\mathrm{S}$ : susceptible) was indicated on top of the lanes of $35 \mathrm{~F}_{2}$ lines with deviations.

Figure 2. Sequence information of the fragment OPA- $09_{910}\left(\mathbf{9 4 2}_{2 \mathrm{bp})}\right.$ and the binding site of the SCAR primers SCOPA09942-F and SCOPA09 ${ }_{942}-\mathrm{R}$ (a); Segregation of SCAR marker SCOPA09 ${ }_{942}$ in a set of $35 \mathrm{~F}_{2}$ progenies (b).

similar to that OPA09910 barring two $\mathrm{F}_{2}$ lines with $\chi^{2}=$ 2.251 and $p$-value $=0.133$ (Figure $2 \mathrm{~b}$ ). Linkage analysis OPA09 $_{910}$, SCOPA09 942 , and IP score for plume moth reaction revealed its position $10.3 \mathrm{cM}(0.102 \mathrm{rf})$ and 1.2 cM (0.012 rf) away from locus $P P M_{1}$ and OPA09 910 , respectively. The screening efficiency of this SCAR marker has been estimated to be $66.37 \%, 91.66 \%$, and $76.0 \%$ in the $116 \mathrm{~F}_{2}, 12 \mathrm{BC}_{1} \mathrm{~F}_{1}$, and $50 \mathrm{~F}_{3}$ lines, respectively (Table 1). This medium-high screening efficiency of the SCAR marker might be attributed to the heterozygous nature of the progenies due to recombination events experienced by the population tested (Chen et al., 2007) vis-a-vis differential expression of target gene in the progenies with respect to the occurrence of this marker (Srivastava et al., 2012). Even this marker may be genomic fragment of a specific gene that regulates the expression plume moth resistance, either wholly or partially. However, these findings substantiates the applicability of this coupling phase SCAR marker (SCOPA09942) in future breeding programs pertaining to plume moth resistance in pigeonpea either individually or coupled with a repulsion phase marker for high precisions.

\section{CONCLUSIONS}

The findings strongly evidenced that OPA09 910 and SCOPA09 $9_{942}$ were closely associated with the locus conferring plume moth resistance in pigeon-pea and the coupling phase SCAR marker SCOPA09 942 will provide ample scope for both screening of the existing germplasm as well as marker aided introgression of the plume moth resistant allele into cultivated genetic background of pigeon-pea.

\section{ACKNOWLEDGEMENTS}

The authors are highly grateful to the Department of Biotechnology, and Department of Science and Technology, Govt. of India, New Delhi, for financial assistance though R\&D projects (F. nr BT/PR13468/ AGR/02/702/2010 of DBT \& F nr SR/FT/LS-92/2009 of DST) to the corresponding author (JP).

Table 1. Screening efficiency of SCOPA09 $9_{942}$ marker in $\mathrm{F}_{2}$ population, $\mathrm{BC}_{1} \mathrm{~F}_{1}$, and $\mathrm{F}_{3}$ progenies.

\begin{tabular}{|c|c|c|c|c|c|}
\hline \multirow[b]{2}{*}{ Population } & \multirow{2}{*}{$\begin{array}{c}\mathrm{Nr} \text { of } \\
\text { progenies }\end{array}$} & \multirow{2}{*}{$\begin{array}{l}\text { Phenotyping identification } \\
\text { (field reaction and antibiosis } \\
\text { assay) }\end{array}$} & \multicolumn{2}{|c|}{ SCOPA09 $9_{942}$ based identification } & \multirow{2}{*}{$\begin{array}{c}\text { Accuracy in } \\
\text { screening }(\%)\end{array}$} \\
\hline & & & Resistant & Susceptible & \\
\hline \multirow[t]{2}{*}{$\mathrm{F}_{2}$} & 116 & Resistant & 63 & 30 & 66.37 \\
\hline & & Susceptible & 9 & 14 & \\
\hline \multirow{2}{*}{$\mathrm{BC}_{1} \mathrm{~F}_{1}$} & 12 & Resistant & 6 & 1 & 91.66 \\
\hline & & Susceptible & 0 & 5 & \\
\hline \multirow[t]{2}{*}{$\mathrm{F}_{3}$} & 50 & Resistant & 24 & 4 & 76.00 \\
\hline & & Susceptible & 8 & 14 & \\
\hline
\end{tabular}




\section{LITERATURE CITED}

Armes, N.J., G.S. Bond, and R.J. Cooter. 1992. The laboratory culture and development of Helicoverpa armigera. Natural Resources Institute Bulletin Series nr 57. 21 p. Natural Resources Institute, Chatham, Kent, UK.

Aruna, R., M. Rao, L.J. Reddy, H.D. Upadhyaya, and H.C. Sharma. 2005. Inheritance of trichomes and resistance to pod borer (Helicoverpa armigera) and their association in interspecific crosses between cultivated pigeonpea (Cajanus cajan) and its wild relative $C$. scarabaeoides. Euphytica 145:247-257.

Chang, J., J. Cui, W. Xue, and Q. Zhang. 2012. Identification of molecular marker for a aphid resistance gene in sorghum and selective efficiency using these markers. Journal of Integrative Agriculture 11:1086-1092.

Chen, H., C. Liu, C. George Kuo, C. Chien, H. Sun, C. Huang, et al. 2007. Development of a molecular marker for bruchid (Callosbrochus chinensis L.) resistance gene in mungbean. Euphytica 157:113-122.

Dhanasekar, P., K.N. Dhumali, and K.S. Reddy. 2010. Identification of RAPD markers linked to plant type gene in pigeonpea. Indian Journal of Biotechnology 9:58-63.

Dianese, E.C., M.E.N. de Fonseca, R. Goldbach, R. Kormelink, A.K. Inoue-Nagata, R.O. Resende, et al. 2010. Development of a locus-specific, co-dominant SCAR marker for assisted-selection of the $S w-5$ (Tospovirus resistance) gene cluster in a wide range of tomato accessions. Molecular Breeding 25:133-142.

Ganapathy, K.N., G.M. Byre, S.C. Venkatesha, R. Ramachandra, B.N. Gnanesh, and G. Girish. 2009. Identification of AFLP markers linked sterility mosaic disease in pigeonpea Cajanus cajan (L.) Millsp. International Journal of Integrative Biology 7:145-149.

Gnanesh, B.N., A. Bohra, M. Sharma, M. Byregowda, S. Pandey, V. Wesley, et al. 2011. Genetic mapping and quantitative trait locus analysis of resistance to sterility mosaic disease in pigeonpea [Cajanus cajan (L.) Millsp.] Field Crop Research 123:53-61.

Grover, A., and D. Pental. 2003. Breeding objectives and requirements for producing transgenics for major field crops of India. Current Science 84:310-320.

Gupta, S.K., A. Charpe, S. Koul, Q.M.R. Haque, and K.V. Prabhu. 2006a. Development and validation of SCAR markers cosegregating with an Agropyron elongatum derived leaf rust resistance gene $L r 24$ in wheat. Euphytica 150:233-240.

Gupta, S.K., A. Charpe, K.V. Prabhu, and Q.M.R. Haque. 2006b. Identification and validation of molecular markers linked to the leaf rust resistance gene $\operatorname{Lr} 19$ in wheat. Theoretical and Applied Genetics 113:1027-1036.

Kosambi, D. 1943. The estimation of map distance from recombination values. Annals of Eugenics 12:172-175.

Kotresh, H., B. Fakrudin, S.M. Punnuri, B.K. Rajkumar, M. Thudi, H. Paramesh, et al. 2006. Identification of two RAPD markers genetically linked to a recessive allele of a Fusarium wilt resistance gene in pigeonpea (Cajanus cajan L. Millsp.) Euphytica 149:113-120.

Li, H., S.G. Zhang, J.M. Gao, C.G. Wang, Y. Zhang, L.W. Qi, et al. 2008. Development of a sequence characterized amplified region (SCAR) marker associated with high rooting ability in Larix. Biologia Plantarum 52:525-528.

Michelmore, R.W., I. Paran, and R.V. Kesseli. 1991. Identification of markers linked to disease resistance genes by bulked segregant analysis: A rapid method to detect markers in specific genomic regions by using segregating populations. Proceedings of National Academy of Science of United States of America 88:9828-9832.
Mishra, R.R. 2013. Molecular mapping of gene(s) conferring resistance to pod borer and pod fly in Cajanus cajan (L.) Millsp. $\mathrm{PhD}$ thesis. Utkal University, Bhubaneswar, India.

Mishra, R.R., A.R. Sahu, S.C. Rath, B. Behera, and J. Panigrahi. 2013. Molecular mapping of locus controlling resistance to Helicoverpa armigera (Hubner) in Cajanus cajan L. (Millspaugh) using interspecific mapping population. The Nucleus 56:91-97.

Panigrahi, J. 2011. Genetic linkage mapping and marker assisted breeding in pigeonpea with special emphasis on resistance to pod borer complex and seed protein content. Scientific and Technical Progress Report, DBT, New Delhi, India.

Saha, P., P. Kalia, H. Sonah, and T.R. Sharma. 2014. Molecular mapping of black rot resistance locus Xcalbo on chromosome 3 in Indian cauliflower (Brassica oleracea var. botrytis L.) Plant Breeding 133:268-274.

Sharma, O.P., J.B. Gopali, S. Yelshetty, O.M. Bambawale, D.K. Garg, and B.B. Bhosle. 2010. Pests of pigeonpea and their management, NCIPM, LBS building, IARI, New Delhi, India.

Sharma, H.C., G. Pampapathy, and L.J. Reddy. 2003. Wild relatives of pigeonpea as a source of resistance to the pod fly (Melanogromyza obtusa Malloch) and pod wasp (Tanaostigmodes cajaninae La Salle). Genetic Resources and Crop Evolution 50:817-824.

Sharma, T.R., M.S. Madhav, B.K. Singh, P. Shanker, T.K. Jana, V. Dalal, et al. 2005. High-resolution mapping, cloning, and molecular characterization of the $P i-k h$ gene of rice, which confers resistance to Magnaporthe grisea. Molecular Genetics and Genomics 274:569-578.

Singh, N.K., D.K. Gupta, K.J. Pawan, K.M. Ajay, S. Dutta, S. Singh, et al. 2012. The first draft of the pigeonpea genome sequence. Journal of Plant Biochemistry and Biotechnology 21:98-112.

Sivaramakrishnan, S., K. Seetha, A. Nageswar Rao, and L. Singh. 1997. RFLP analysis of cytoplasmic male-sterile lines of pigeonpea (Cajanus cajan (L.) Millsp.) developed by interspecific crosses. Euphytica 93:307-312.

Srivastava, M.K., C.N. Li, and R.Y. Li. 2012. Development of sequence characterized amplified region (SCAR) marker for identifying drought tolerant sugarcane genotype. Australian Journal of Crop Science 6:763-767.

Srivastava, R.K., S.K. Mishra, A.K. Singh, and T. Mohapatra. 2012. Development of a coupling-phase SCAR marker linked to the powdery mildew resistance gene 'erl' in pea (Pisum sativum L.) Euphytica 186:855-866.

Sujana, G., H.C. Sharma, and D. Manohar Rao. 2008. Antixenosis and antibiosis components of resistance to pod borer, Helicoverpa armigera in wild relatives of pigeonpea. International Journal of Tropical Insect Science 28:191-200.

Varshney, R.K., W. Chen, Y. Li, A.K. Bharti, R.K. Saxena, J.A. Schlueter, et al. 2012. Draft genome sequence of pigeonpea (Cajanus cajan), an orphan legume crop of resource-poor farmers. Nature Biotechnology 30:83-89.

Verulkar, S.B., D.P. Singh, and A.K. Bhattacharya. 1997. Inheritance of resistance to pod fly and pod borer in the interspecific cross of pigeonpea. Theoretical and Applied Genetics 95:506-508.

Williams, J.G.K., A.R. Kubelik, K.J. Livak, J.A. Rafalski, and S.V. Tingey. 1990. DNA polymorphisms amplified by arbitrary primers are useful as genetic marker. Nucleic Acids Research 18:6531-6535. 